\title{
Особенности строения главной жилки листа некоторых видов рода Salix L. (Salicaceae Mirb)
}

\section{Structure peculiarities of the main leaf vein of some species from the genus Salix L. (Salicaceae Mirb)}

\author{
Дрожжина В. Н. \\ Drozhzhina V. N. \\ Воронежский государственный педагогический университет, г. Воронеж, Россия. E-mail: o.drozhzhin@gmail.com \\ Voronezh State Pedagogical University, Voronezh, Russia
}

\begin{abstract}
Peферат. Проведенные исследования показывают индивидуальные особенности в строении главной жилки листа для каждого представителя рода Salix L. Данные показатели можно использовать для уточнения видовой принадлежности ив. Наиболее информативными признаками являются: положение главной жилки по отношению к мезофиллу листа; форма главной жилки на поперечном срезе; положение проводящего пучка жилки по отношению к условной линии, делящей лист на верхнюю и нижнюю части; форма проводящего пучка, особенности расположения столбчатого мезофилла в области главной жилки. Менее значимые признаки: наличие кристаллов оксалата кальция; характеристика и положение трихом; объем паренхимы в центральной части проводящего пучка; степень развития паренхимной и склеренхимной обкладки.
\end{abstract}

Ключевые слова. Главная жилка, мезофилл, паренхимная обкладка, проводящий пучок, склеренхимная обкладка.

Summary. Studies show individual characteristics in the structure of the leaf's main vein for each representative of the genus Salix L. These indicators can be used for identification species of willows. The most informative features are: the position of the main vein with respect to the leaf mesophyll; the shape of the main vein on the cross section; the position of the conducting bundle of the vein with respect to the conditional line, dividing the sheet into the upper and lower parts; the shape of the conducting beam, especially the location of the columnar mesophyll in the main vein. Less important characteristics: the presence of crystals of calcium oxalate; the characteristics and position of the trichomes; the volume of the parenchyma in the Central part of the conductive beam; the degree of development of the wheat plant's and sclerenchyma lining.

Key words. Conducting bundle, main vein, mesophyll, parenchymal lining, sclerenchymal lining.

Представители рода Salix L. отличаются морфологическим полиморфизмом в строении листовой пластинки. Это нередко затрудняет видовую диагностику. Проблемы в определении ив также связаны с наличием большого количества гибридов, с двудомностью представителей данного рода и отличиями на уровне разных по полу особей (Морозов, 1966; Скворцов, 1968). Анатомические показатели оказываются весьма информативными в целях видовой диагностики. Параметры мезофилла листа позволяют разделить виды ив на несколько групп по наличию гиподермы, типу мезофилла листа, особенностям расположения устьиц. Изучение анатомического строения главной жилки листа показало качественные и количественные различия для видов рода Salix L. и возможность использования этих особенностей для уточнения систематической принадлежности отдельных особей.

В качестве объектов исследования выбраны представители рода Salix L., наиболее часто встречающиеся на территории Воронежской области и использующиеся для озеленения. Это Salix alba L., S. acutifolia Wilb., S. caprea L., S. cinerea L., S. myrsinifolia Salisb., S. purpurea L., S. viminalis L. 
Для изучения особенностей анатомического строения листьев ив использовался как свежий, так и фиксированный в $70^{\circ}-$ м этиловом спирте материал. Сбор материала проводили в июле - августе месяце. Листья отбирали из средней части годичных пролептических побегов. Побеги отбирали из средней части кроны модельных деревьев. Препараты готовили из средней части листа. Срезы изготавливали на санном микротоме с замораживающим столиком (толщина срезов - 15-20 мкм). Исследование микропрепаратов проводили на микроскопе «Jenamed».

Листья ив полные, простые, цельные. Вдоль листовой пластинки проходит главная жилка, которая проходит через верхушку листа, поэтому называется проходящей. Тип жилкования перисто-сетчатый. Жилки второго и последующих порядков не доходят до края листовой пластинки, они ветвятся, и эти многочисленные ответвления соединяются друг с другом, образуя сетку, петель они не образуют. Такой тип жилкования является несовершенным (Афонин, 2003; Афонин, 2005).

Главная жилка листа исследуемых видов отличается своим положением по отношению к остальной части листовой пластинки. Одна группа видов характеризуется выступающей жилкой с абаксиальной стороны листа. Это такие виды как S. cinerea, S. myrsinifolia, S. viminalis. С двух сторон, с абаксиальной и адаксиальной, выступает жилка у S. acutifolia, S. alba, S. caprea. Некоторые виды отличаются жилками, практически погруженными в толщу мезофилла, как например, S. purpurea.

Зрелые листья одних видов довольно густо опушены, особенно на абаксиальной части - это S. alba, S. cinerea, $S$. viminalis. Только на абаксиальной стороне опушены взрослые листья $S$. сарrea и S. myrsinifolia. Опушение отсутствует на развитых листья у S. acutifolia, S. purpurea (Валягина-Малютина, 2004). Анализ анатомического строения главной жилки объектов исследования дал следующие результаты.

У S. cinerea толщина главной жилки почти в 3 раза превышает толщину листовой пластинки. На адаксиальной стороне жилка ненамного приподнимается над листовой пластинкой и имеет округлые очертания, зато на абаксиальной стороне жилка значительно выдается над поверхностью листа, переход от жилки к листовой пластинке довольно резкий. В области жилки под верхней эпидермой располагается 3-4 слоя колленхимы, тогда как на нижней стороне ее количество не превышает двух слоев. Паренхимная обкладка на верхней стороне представлена 2-3 слоями, а снизу их количество увеличивается до 5-6. Друзы оксалата кальция встречаются преимущественно в нижней части паренхимы. Проводящий пучок в главной жилке имеет более широкую нижнюю часть, из-за чего его очертания имеют форму усеченного треугольника или трапеции. У отдельных экземпляров можно характеризовать форму как овальную изогнутую. Паренхима в средней части пучка мощно развита и может формировать до пяти слоев, состоящих из мелких тонкостенных клеток. Склеренхимная обкладка вокруг пучка формирует сплошное кольцо. По бокам пучка она выражена слабо, а сверху и снизу сложена двумя рядами клеток. По сравнению с другими видами склеренхима наименее развита. Столбчатый мезофилл глубоко заходит в область главной жилки, за счет чего создается своеобразный рисунок отличный для разных видов ив. Мезофилл отделен от пучка крупными клетками неспециализированной паренхимы. Граница столбчатого мезофилла устремляется к верхней стороне листа. Условная линия, делящая мезофилл пополам, оставляет проводящий пучок жилки ниже этой линии.

S. myrsinifolia отличается достаточно толстой листовой пластинкой. Главная жилка примерно в 3 раза толще мезофилла. На адаксиальной стороне жилка оказывается несколько вдавленной в толщу мезофилла. На абаксиальной стороне ткани листовой пластинки постепенно и очень плавно переходят в главную жилку. Под верхней и нижней эпидермой располагается мощная колленхима, сложенная 3-4 слоями клеток. Паренхимная обкладка образована крупными клетками, количество слоев небольшое 3 слоя. Кристаллы оксалата кальция в паренхиме не отмечены. Проводящий пучок имеет овальные очертания, длина его в 2,5 раза больше ширины. Запасающая паренхима в центре пучка развита слабо, 1-2 слоя мелких клеток. Склеренхимная обкладка полностью окружает проводящий пучок и наиболее выражена она на нижней стороне. Мезофилл листа очень глубоко заходит в область главной жилки. В целом все клетки жилки, как и клетки других тканей у S. myrsinifolia, довольно крупные по сравнению с другими видами ив. Граница столбчатого мезофилла устремляется к верхней стороне листа. Условная линия, делящая мезофилл пополам, оставляет проводящий пучок ниже этой линии. 
Главная жилка листа $S$. сарrea самая мощная среди всех исследуемых видов. Толщина листовой пластинки в области мезофилла тоньше в 5 раз, чем в области самой жилки. Жилка значительно выступает как с верхней, так и с нижней стороны листа, снизу гораздо больше. Под верхней и нижней эпидермой располагаются 3-4 слоя клеток колленхимы. Далее следует обкладка из клеток паренхимы, очень мощно она развита на нижней стороне жилки, количество слоев может достигать 5-6. На верхней стороне обкладка очень узкая и представлена двумя слоями клеток. В главной жилке S. caprea встречается много кристаллов оксалата кальция, особенно на абаксиальной стороне. Проводящий пучок имеет овальные очертания на поперечном срезе, в некоторых случаях даже близкие к округлым. Высота и ширина пучка примерно одинаковые. В центре пучка хорошо развита паренхима, содержащая большое количество друз. Паренхима крупноклетная, располагается в три слоя. Склеренхимная обкладка окружает пучок, но сильнее развита на абаксиальной стороне. Клетки столбчатого мезофилла доходят практически до самого проводящего пучка, они отделены лишь несколькими клетками склеренхимной обкладки. Линия мезофилла направлена вниз. Условная линия, делящая мезофилл пополам, проходит через паренхиму проводящего пучка.

Толщина листовой пластинки $S$. purpurea достигает 180 мкм, т. е. можно сказать, что это вид с толстой листовой пластинкой. Толщина жилки в 2 раза больше толщины мезофилла. Причем жилка практически одинаково выдается как над абаксиальной, так и над адаксиальной стороной. Как сверху, так и снизу жилка плавно переходит в мезофилл. Толщина колленхимы и паренхимной обкладки примерно одинаковые. Как снизу, так и сверху эти ткани расположены в 2 слоя. Друзы встречаются в неспециализированной паренхиме редко. Форма проводящего пучка овальная, несколько изогнутая, с выпуклой стороной, обращенной на абаксиальную сторону. Ширина пучка на поперечном сечении в 2 раза больше высоты. Склеренхимная обкладка вокруг пучка развита равномерно со всех сторон. Мезофилл отграничен от проводящего пучка почти прямой линией. Если провести условную линию, разделяющую мезофилл листа пополам (на верхнюю и нижнюю части), то проводящий пучок окажется разделен пополам по линии паренхимы пучка.

S. acutifolia отличается очень крупной главной жилкой, которая почти одинаково выдается как с адаксиальной, так и с абаксиальной стороны листа. Данный вид имеет среднюю по толщине листовую пластинку - 150 мкм в среднем. Толщина жилки более чем в 3 раза превышает толщину в области мезофилла. Колленхима расположена в 2 слоя и под верхней, и под нижней эпидермой. Клетки неспециализированной паренхимы располагаются в 3 слоя. И паренхимные клетки, и клетки колленхимы довольно крупные. Друзы обнаружены только на адаксиальной части жилки. Проводящий пучок самый крупный из всех исследуемых видов, его ширина в 3 раза больше высоты, т.е. он имеет вытянутые овальные очертания. Паренхима в средней части пучка представлена очень узкой полоской, состоящей из мелких клеток. Условная линия середины делит пополам мезофилл и проводящий пучок.

Главная жилка $S$. alba выступает с двух сторон листа, но с нижней стороны несколько сильнее. В жилке очень мощно развиты механические ткани колленхима и склеренхима. Доля неспециализированной паренхимы у этого вида ивы даже несколько меньше, чем доля тканей механических. Наиболее развита колленхима на верхней стороне жилки, клетки крупные, располагаются в 3 слоя. Очевидно, это связано с ее небольшой распространенностью по ширине жилки, так как мезофилл очень глубоко заходит в ткани жилки, и особенно с верхней стороны. Проводящий пучок имеет овальные очертания и заметно вытянут по ширине. Нижняя сторона пучка более выпуклая, чем верхняя. В центре пучка хорошо развита паренхима. друзы в тканях жилки не обнаружены. Данный вид ивы отличается густо опушенными листьями. Трихомы располагаются на обеих сторонах листа как в области мезофилла, так и главной жилки.

На адаксиальной стороне главная жилка S. viminalis практически не выступает над поверхностью листа. На абаксиальной стороне, наоборот, главная жилка значительно выдается над поверхностью листа. Толщина главной жилки в 4 раза превышает толщину листовой пластинки. Граница между жилкой и мезофиллом листа на нижней стороне очень резкая. В области жилки в листе мощно развита колленхима. Она представлена тремя слоями клеток уголковой колленхимы. За колленхимой располагаются клетки неспециализированной паренхимы, которые образуют мощную паренхимную обкладку. Проводящий пучок жилки окружен склеренхимной обкладкой, которая более мощно развита 
на верхней стороне пучка. Ксилема пучка разделена на 2 части, как и у других видов ив. Адаксиальная часть меньше абаксиальной. Между ними располагается участок паренхимных клеток. Общие очертания пучка - это усеченная трапеция. Мезофилл листа глубоко заходит в область главной жилки и спускается по бокам от проводящего пучка на нижнюю сторону жилки.

Общими чертами в строении главной жилки ив являются следующие особенности. Под эпидермой располагается колленхима, количество рядов от 3 до 6, наиболее мощно развита она на абаксиальной части. Паренхима главной жилки, образующая паренхимную обкладку, представлена крупными тонкостенными клетками, содержащими большое количество друз оксалата кальция. Чаще всего друзы сосредоточены на границе между паренхимной и склеренхимной обкладками. Склеренхимная обкладка у исследуемых видов образует сплошное кольцо вокруг проводящего пучка. Проводящий пучок в главной жилке один, тогда как у тополей их несколько. В центре проводящего пучка всех видов развита так называемая сердцевина, представленная паренхимными клетками. Мезофилл листовой пластинки заходит в область главной жилки по-разному в зависимости от вида растения и от степени погружения жилки в ткани листа.

Особенности строения жилок можно использовать для диагностики видов. Наряду со строением мезофилла листа, особенности строения жилки являются весьма информативными.

\section{ЛИТЕРАТУРА}

Афонин А. $\boldsymbol{A}$. Ивы Брянского лесного массива. - Брянск: БГУ, 2003. - 237 с.

$\boldsymbol{A ф о о н и н ~} \boldsymbol{A}$. $\boldsymbol{A}$. Ивы Брянского лесного массива: проблема повышения продуктивности и устойчивости насаждений и пути ее решения. - Брянск: Брянск гос. ун-т., 2005. -172 с.

Валягина-Малютина E. T. Ивы европейской части России. - М.: Изд-во КМК, 2004. - 217 с.

Морозов И. Р. Определитель ив и их культура. - М.: Лесн. пром-сть, 1966. - 254 с.

Скворцов А. К. Ивы СССР. - М.: Наука, 1968. - 262 с. 